\title{
Contamination Level, Ecological Risk, and Source Identification of Heavy Metals in the Hyporheic Zone of the Weihe River, China
}

\author{
Muhammad Irfan Ahamad ${ }^{1,2} \mathbb{D}^{1}$, Jinxi Song $1,2,3, * \mathbb{C}$, Haotian Sun ${ }^{1,2}$, Xinxin Wang ${ }^{1,2}$, \\ Muhammad Sajid Mehmood ${ }^{1}{ }^{1}$, Muhammad Sajid ${ }^{4,5}{ }^{-}$, Ping Su ${ }^{1,2}$ and Asif Jamal Khan ${ }^{1,2}$ \\ 1 Shaanxi Key Laboratory of Earth Surface System and Environmental Carrying Capacity, College of Urban \\ and Environmental Sciences, Northwest University, Xi'an 710127, China; irfan@stumail.nwu.edu.cn (M.I.A.); \\ sunhaotian@nwu.edu.cn (H.S.); xinxinwang@stumail.nwu.edu.cn (X.W.); \\ m.sajid.mehmood@hotmail.com (M.S.M.); pingsu@stumail.nwu.edu.cn (P.S.); asifj_khan@yahoo.com (A.J.K.) \\ 2 Institute of Qinling Mountains, Northwest University, Xi'an 710127, China \\ 3 State Key Laboratory of Soil Erosion and Dryland Farming on the Loess Plateau, Institute of Soil and Water \\ Conservation, Chinese Academy of Sciences and Ministry of Water Resources, Yangling 712100, China \\ 4 Key Laboratory for Industrial Biocatalysis, Ministry of Education of China, Institute of Applied Chemistry, \\ Department of Chemical Engineering, Tsinghua University, Beijing 100084, China; \\ wang-li17@mails.tsinghua.edu.cn \\ 5 Department of Chemical Engineering, University of Gujrat, Gujrat 50700, Pakistan \\ * Correspondence: jinxisong@nwu.edu.cn; Tel.: +86-29-8830-8596
}

Received: 16 December 2019; Accepted: 5 February 2020; Published: 7 February 2020

\begin{abstract}
The sediment pollution caused by different metals has attracted a great deal of attention because of the toxicity, persistence, and bio-accumulation. This study focuses on heavy metals in the hyporheic sediment of the Weihe River, China. Contamination levels of metals were examined by using "geo-accumulation index, enrichment factor, and contamination factor" while ecological risk of metals were determined by "potential ecological risk and risk index". The pollutant accumulation of metals ranked as follows: "manganese $(\mathrm{Mn})>$ chromium $(\mathrm{Cr})>$ zinc $(\mathrm{Zn})>$ copper $(\mathrm{Cu})>\operatorname{nickel}(\mathrm{Ni})>\operatorname{arsenic}(\mathrm{As})>$ lead $(\mathrm{Pb})^{\prime \prime}$. The geo-accumulation index identified arsenic as class 1 (uncontaminated to moderate contamination), whereas $\mathrm{Cu}, \mathrm{Cr}, \mathrm{Ni}, \mathrm{Zn}, \mathrm{Pb}$, and $\mathrm{Mn}$ were classified as class 0 (uncontaminated). According to the enrichment factor, arsenic originated through anthropogenic activities and $\mathrm{Cr}, \mathrm{Ni}, \mathrm{Cu}, \mathrm{Zn}$, and $\mathrm{Pb}$ were mainly controlled by natural sources. The contamination factor elucidated that sediments were moderately polluted by ( $\mathrm{As}, \mathrm{Cr}, \mathrm{Cu}, \mathrm{Zn}, \mathrm{Mn}$, and $\mathrm{Pb}$ ), whereas Ni slightly contaminated the sediments of the Weihe River. All metals posed a low ecological risk in the study area. The risk index revealed that contribution of arsenic (53.43\%) was higher than half of the total risk.
\end{abstract}

Keywords: sediments; heavy metals; geo-accumulation index; potential ecological risk; Weihe River

\section{Introduction}

The hyporheic zone is regarded as the immersed region underneath the riverbed, where the fraternization of ground and surface water typically happens [1]. It is a dynamic region that acts as a transitional zone for water exchange, material cycles, solute transport, and other ecological service functions [2]. The rivers perform multiple functions, including aquaculture, water transportation, irrigation, as well as provide domestic water. According to different policies and scientific objectives, several ecological functions of the river have been evaluated and studied, which include quality of water [3], hydrological processes [4], animal population dynamics [5], quality of sediments [6], 
and composition of vegetation [7]. Among these factors, the quality of the sediments has attracted particular attention, since the sediment not only acts as a reservoir for pollutants but also interacts with different factors [8]. For example, the sediment quality is related to hydrological connection, vegetation characteristics, quality of water, industrial material and process, land use, and mineral type [9]. As a result of industrial development, the water environment is increasingly exposed to metal pollution, due to their persistence, ability to incorporate within the food chain, and environmental bioaccumulation [10,11]. Due to hydrolysis, co-precipitation, and adsorption, heavy metals are predominantly deposited in the sediment, with only a few dissolved in water [12].

Pollution caused by heavy metals is regarded as a severe risk to the river environment because of its chronic nature, toxicity, non-biodegradability, as well as bioaccumulation [13]. Heavy metal in polluted habitats can accumulate in river flora and fauna, which may enter into the food chain and create health problems [14]. Sediments are ecologically valuable constituents of the river environment [15]. Sediments acting as a carrier are also the secondary sources of pollutants in the river environment [16]. Therefore, the evaluation of the river sediments is a valuable approach to assess metal pollution in a given area [17].

Heavy metals have attracted researchers' attention because of their toxicity, bioaccumulation, non-degradability, and enormous sources, together with their persistence in the aquatic environment [18]. After being released, heavy metals may be distributed in various components of the river environment [19]. As a result, simply a small quantity of heavy metals stay inside those water columns, and the maximum amount accumulated within the sediment [20]. Particularly, metals are combined with sediments by numerous mechanisms, including co-precipitation, surface adsorption particle, ion exchange, as well as complexation upon organic matters [21,22].

Within sediments, metals originate either from natural sources (for example atmospheric precipitation, ore deposits, geological weathering, disintegration of parent rocks because of storms, wind bioturbation, and waves), or by anthropogenic activities (for example mining, transportation industrial emission, smelting, fuel production, electroplating, sludge dumping, power transmission, dust, intensive urban and agricultural activities, and wastewater irrigation) [23-25]. Within the soil ecological community, the toxicity along with the mobility of heavy metals depends on different factors, including metal binding condition, chemical type, total accumulation, and properties of metals [26].

An enormous portion of heavy metals is directed toward aquatic surroundings and accumulated in the sediments, which can (a) contaminate water, causing the death of a regional aquatic population and accumulate in plants by means of irrigation [27]; (b) release into water by sediment re-suspension, desorption and adsorption reactions, oxidation and reduction reaction, together with degradation of the organisms [28,29].

Heavy metals are categorized as essential and nonessential metals. Essential metals occur naturally, while the nonessential metals, having no positive effect, are considered hazardous even in low quantity [30]. However, excessive use of essential metals has been linked to cellular and systemic disorders [31]. Further, in the long term, the accumulation of these metals in soil can lead to the deterioration of agricultural land, eutrophication, and the absorption of toxic substances [32]. In the last few years, natural sources and anthropogenic activities have contributed to an increasing level of heavy metals. Therefore, an evaluation is necessary to measure heavy metals concentration and understand the soil quality. There is a demanding need to carry out scientific research in terms of heavy metal pollution.

Our work addresses the distribution, contamination levels, metal sources, and heavy metal ecological risks. In this study, samples have been taken from several selected locations from the research area. This study aims to (1) evaluate the heavy metals "Arsenic (As), Chromium (Cr), Copper $(\mathrm{Cu})$, Nickel (Ni), Lead ( $\mathrm{Pb})$, Zinc $(\mathrm{Zn})$, and Manganese (Mn)"; (2) assess different levels of pollution, which include "geo-accumulation index, enrichment factor and contamination factor"; (3) assess the "potential ecological risk and ecological risk index" of metals in sediment; (4) evaluate the correlation and source identification of heavy metals. 


\section{Materials and Methods}

\subsection{Description of Study Area}

The Weihe River is the biggest tributary of the Yellow River, having a length of almost $818 \mathrm{Km}$ and flowing into the Yellow River in the Shaanxi Province (Figure 1). As the "mother river" of the Guanzhong region, the Weihe River is the primary agricultural and industrial region in northwest China [33]. The Weihe River is the main water supplier in central China and it covers an area of almost $6.67 \times 10^{4} \mathrm{~km}^{2}$ in Shaanxi province [1,34]. In the province, average annual river flow and sediment yield are $103.7 \times 10^{8} \mathrm{~m}^{3}$ and $5.8 \times 10^{8} \mathrm{t}$, respectively, which accounts for one-third of the sediment load of the Yellow River. Loess Plateau, Qinling Mountains, and the Guanzhong Plain are three topographic classes covering the river basin.

The Weihe River is under a typical continental monsoon climate with dry, cold winters as well as rainy, hot summers, with heavy rainfall from June to October. Moreover, the river basin is predominantly covered with loess because of severe sediment transport and erosion [1].

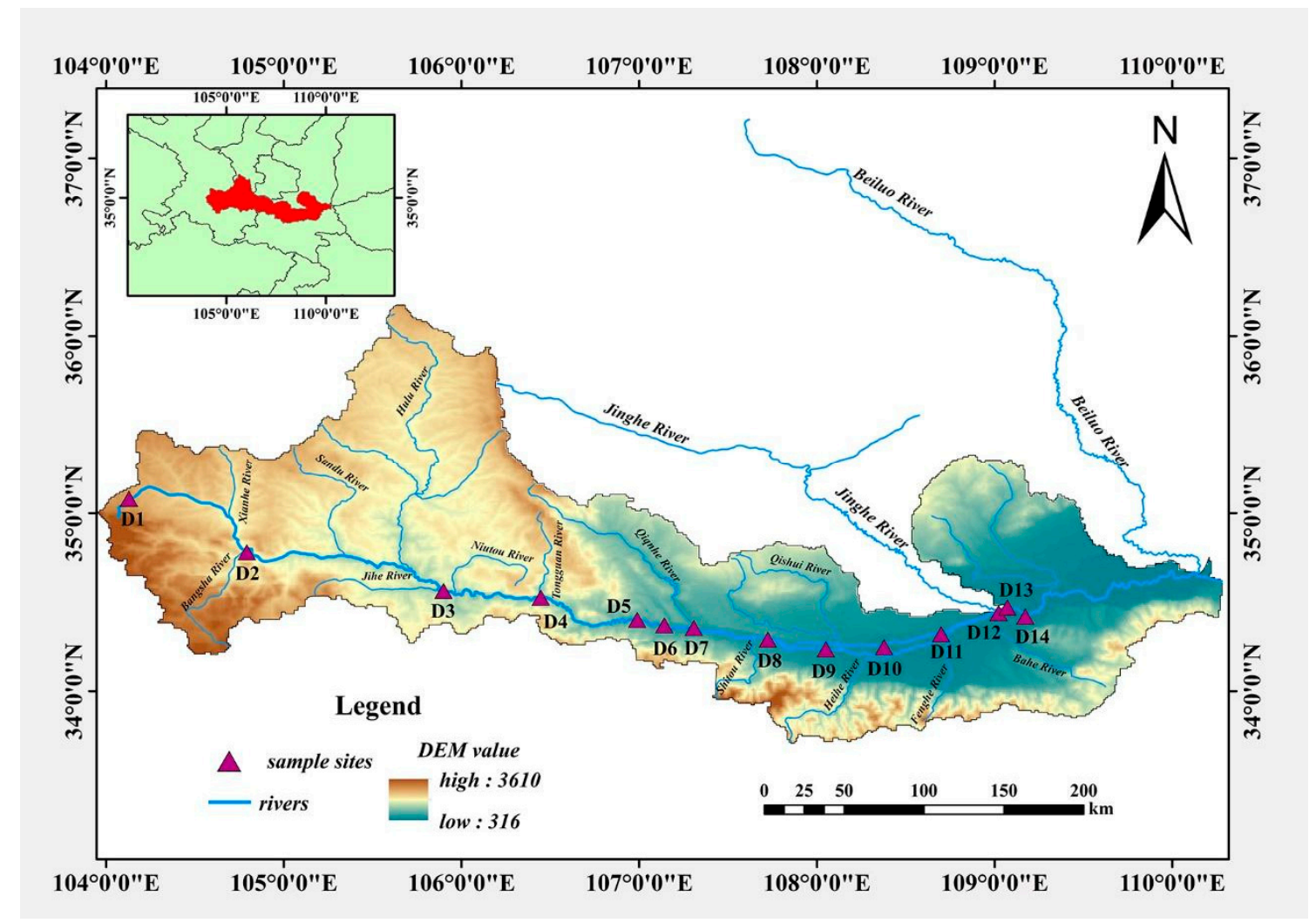

Figure 1. Sampling sites and study area maps.

\subsection{Sampling}

Sediment samples were collected from different sites of the Weihe River having the same properties. We selected fourteen sites from the mainstream of the river, which included upstream (D1-D6), middle stream (D7-D11), and downstream (D12-D14). These sites covered the overall mainstream and represented the pollution situation. Each sample consisted of triplicate. A "Global Positioning System" was used throughout the sampling to locate the exact location of the sampling sites. A thin-walled transparent poly-carbon tube with an opening at both ends was put into the riverbed sediment for samples. A piston column sampler was used where needed. The samples were preserved in polyethylene sampling bags and shifted back to a research laboratory within $12 \mathrm{~h}$ for further analysis. 


\subsection{Quality Control and Quality Assurance}

Throughout the study, we assured quality control and quality assurance. Accuracy and precision were verified using reference materials sediment-certified samples "GBW07311 (GSD-11) and GBW07366 (GSD-23) of the National Center of China". Instruments were calibrated before every analysis. The blanks in every set had been tested in duplicates using the same techniques. The results presented are the average values of duplicated analysis. For repeat tests, samples were selected randomly. All glasses, plastics, and quartz were cleaned in $10 \% \mathrm{HNO}_{3}$, and ultrapure water $\left(18.25 \mathrm{M} \mathrm{ohm} \mathrm{cm}^{-1}\right)$ was used to rinse every time.

\subsection{Analysis of Samples}

Stone and plant pieces were separated from the sediment samples. The sediments were grinded with agate mortar, powdered, and passed through 200 mesh nylon sieves, and finally stored in glass bottles that had been washed by nitric acid and water (3:1). For the evaluation of metal contents, concentrated $\mathrm{HNO}_{3}, \mathrm{HF}$, and $\mathrm{H}_{2} \mathrm{O}_{2}$ were used to digest sediment samples [35]. A high temperature and high-pressure digester and electro thermal plate digestion were used during the digestion process. The filtration of the digested solution was done by using a filter $(0.45 \mu \mathrm{m})$ "Xinya Purify Device Company, Shanghai, China". Next, $\mathrm{Cu}, \mathrm{Cr}, \mathrm{Ni}, \mathrm{Zn}$, and $\mathrm{Pb}$ were assessed by an "Inductively coupled plasma mass spectrometer" (X series 2) manufactured by American Thermoelectric. Moreover, Fe and Mn were assessed by the "Inductively coupled plasma emission spectrometer" (Icap7400) manufactured by American Thermoelectric and Arsenic, by a two-channel atomic fluorescence photometer (AFS2000) manufactured by Beijing Haiguang.

\subsection{Calculation of Pollution Levels}

Various techniques had been used to estimate metal pollution in sediments. In this research, pollution levels, specifically "geo-accumulation index, enrichment factor, and contamination factor," have been determined to evaluate different pollution levels. The selection of background value is the essential parameter to interpret useful geochemical data; average crustal value has been used as a background value by various researchers [24,36-38]. In this study, the average crustal value of metals presented by "Turekian and Wedepohl" has been used as the background value (Table S1) [39].

\subsubsection{Geo-Accumulation Index (Igeo)}

Muller presented the concept of the Igeo, which is used to assess different pollution levels in soil and sediments. [40]. Igeo is measured by Equation (1).

$$
\text { Igeo }=\log 2 \frac{C_{n}}{1.5 * B_{n}}
$$

In Equation (1), $C_{n}$ shows measured metal contents in samples, $B_{n}$ symbolize reference or background values of metal, 1.5 is a factor that is used to calculate possible changes in background value. By using the average shale value, the geo-accumulation index was calculated [41]. Igeo comprises seven different classes (Table 1) [6].

Table 1. Geo-accumulation index (Igeo) and Enrichment factor (EF) classification.

\begin{tabular}{cccc}
\hline & Igeo & EF \\
\hline Igeo Classes & Sediment quality & EF Class & Sediment quality \\
Igeo $\leq 0$ & No pollution & $E F<1$ & No pollution \\
Igeo $=0-1$ & No to moderate pollution & $E F<2$ & Very small pollution \\
Igeo $=1-2$ & Moderate pollution & $2<E F<5$ & Deficiency to small pollution \\
Igeo $=2-3$ & Moderate to heavy pollution & $E F=5-10$ & Moderate to high pollution \\
Igeo $=3-4$ & Heavy pollution & $E F=10-25$ & High pollution \\
Igeo $=4-5$ & Heavy to extreme pollution & $E F=25-50$ & Very high pollution \\
Igeo $\geq 5$ & Extreme pollution & $E F>50$ & Exceptionally high pollution \\
\hline
\end{tabular}




\subsubsection{Enrichment Factor (EF)}

$\mathrm{EF}$ is an excellent technique to calculate the proportion of pollutants in sediments [42]. EF for every metal was calculated to estimate how much metals are originated from anthropogenic activities in sediments $[43,44]$. EF is mostly used to differentiate the source of metals, which can be natural or anthropogenic [45]. It involves the stabilization of sediments relative to reference elements, for example, scandium (Sc), titanium (Ti), and manganese (Mn) [46], iron (Fe), and aluminum (Al) [47]. Anthropogenic metal enrichment was measured by using manganese $(\mathrm{Mn})$, a reference element as most symbolized by Loska [48]. The equation given below is used to estimate the EF.

$$
E F=\frac{\left(\frac{C_{n}}{C_{M n}}\right) \text { sample }}{\left(\frac{C_{n}}{C_{M n}}\right) \text { Background value }}
$$

Enrichment factor is the proportion between the desired sample to the world average background value from "Turekian and Wedepohl" [39]. Various contamination classes are determined with the help of enrichment factors (Table 1) [49,50].

\subsubsection{Contamination Factor $(\mathrm{CF})$}

$\mathrm{CF}$ is deemed as a useful tool to monitor contamination in sediments over time. It is the ratio of every metal in the present sample to the background values in the same metal [36].

$$
C F=\frac{C_{\text {heavy metal }}}{C_{\text {background }}}
$$

The contamination degrees can be categorized according to their values from 1 to 6 "if $C F<1$, low pollution; $1<C F<3$, moderate pollution; $3<C F<6$, considerable pollution; $C F>6$, very high pollution" [51]

\subsection{Potential Ecological Risk and Risk Index}

Hakanson presented a technique that was used to measure different levels of ecological risk in river sediment [52,53]. This approach assesses different levels of pollution in sediment while combining the environmental and ecological risks with toxicology, to assess potential risks and levels of metal pollution index [54].

$$
\begin{gathered}
E_{r}^{i}=T_{r}^{i} * \frac{C_{i}}{C_{0}} \\
R I=\sum_{i=1}^{n} T_{r}^{i} * \frac{C_{i}}{C_{O}}
\end{gathered}
$$

where $C_{i}$ represents the concentration in sediment $\mathrm{i} ; C_{o}$ shows the concentration in reference; $T_{r}^{i}$ describes the toxicity factor, which was already described as: $A s=10, C u=P b=N i=5, Z n=M n=1$, $C r=2$ [52,53]; $E_{r}^{i}$ represents the "ecological risk," and RI denotes the overall "risk index" of metal. Different levels of risk index are presented in Table 2.

Table 2. Ecological risk and risk index (RI) classification.

\begin{tabular}{ccccc}
\hline ER Level & Value of ER & Risk & Value of RI & Risk \\
\hline 0 & $E R<40$ & Low & $R I<110$ & Low \\
1 & $E R=40-80$ & Moderate & $R I=110-200$ & Moderate \\
2 & $E R=80-160$ & Considerable & $R I=200-400$ & Considerable \\
3 & $E R=160-320$ & High & $R I \geq 400$ & Very High \\
4 & $E R \geq 320$ & Very High & & \\
\hline
\end{tabular}




\subsection{Statistical Analysis}

Information about the source of contaminants was attained through the details of sediment conditions and statistical analysis [55]. Pearson's correlation was used to examine the correlation between the concentrations of different metals. The PCA was used to extract a subset of the factors from the original variable [52,56]. Kaiser-Meyer-Olkin, the Bartlett sphericity test, as well as the covariance matrix were used on the base of eigenvalue to validate the PCA [8,57]. Varimax rotation was selected to measure metals and the rate of contribution for eigenvalues $>1$ in principal components [53].

\section{Results}

\subsection{Estimation of Heavy Metals in the Sediments of the Weihe River}

The average concentration of $\mathrm{As}, \mathrm{Cr}, \mathrm{Ni}, \mathrm{Cu}, \mathrm{Zn}, \mathrm{Pb}$, and Mn were 29.16, 109.98, 41.47, 52.37, $103.47,24.44,888.29 \mathrm{mg} / \mathrm{kg}$ respectively. The concentration of $\mathrm{Mn}$ was higher than other heavy metals, whereas low concentrations of $\mathrm{Pb}$ were detected. The concentrations of $\mathrm{Cr}$ ranked second highest in sediment samples. The average value of As was $29.16 \mathrm{mg} / \mathrm{kg}$, which is greater than the average shale value $(13 \mathrm{mg} / \mathrm{kg})$. Meanwhile, $\mathrm{Pb}$ average concentration was $24.44 \mathrm{mg} / \mathrm{kg}$. The detailed concentrations of metals obtained from sediments are presented in Table 3.

Table 3. Variation in concentrations of heavy metal in the sediment from different stations of the Weihe River.

\begin{tabular}{cccccccc}
\hline Location & As & $\mathbf{C r}$ & $\mathbf{N i}$ & $\mathbf{C u}$ & $\mathbf{Z n}$ & $\mathbf{P b}$ & $\mathbf{M n}$ \\
\hline D1 & 27.55 & 84.64 & 38.76 & 69.34 & 75.84 & 16.72 & 716.34 \\
D2 & 31.98 & 60.54 & 42.83 & 55.77 & 133.27 & 35.42 & 918.44 \\
D3 & 39.93 & 122.66 & 39.28 & 52.63 & 108.65 & 25.94 & 1036.63 \\
D4 & 22.89 & 108.79 & 37.28 & 57.44 & 82.98 & 24.25 & 1212.79 \\
D5 & 35.43 & 142.93 & 22.98 & 18.23 & 95.75 & 17.46 & 1152.61 \\
D6 & 29.38 & 104.74 & 32.63 & 35.53 & 111.45 & 17.68 & 842.41 \\
D7 & 26.62 & 138.67 & 15.43 & 68.40 & 104.27 & 27.57 & 519.25 \\
D8 & 35.98 & 117.87 & 46.68 & 58.47 & 95.64 & 26.49 & 738.43 \\
D9 & 23.69 & 93.78 & 39.98 & 35.39 & 71.32 & 33.30 & 686.94 \\
D10 & 26.88 & 108.67 & 46.24 & 62.43 & 78.74 & 21.63 & 1088.73 \\
D11 & 18.43 & 105.67 & 62.38 & 53.45 & 141.83 & 19.75 & 828.73 \\
D12 & 20.67 & 98.46 & 54.94 & 32.30 & 88.87 & 23.99 & 940.64 \\
D13 & 29.59 & 113.87 & 57.46 & 65.94 & 143.64 & 36.39 & 718.64 \\
D14 & 39.24 & 138.37 & 43.76 & 67.93 & 116.28 & 15.62 & 1035.43 \\
Minimum & 18.43 & 60.54 & 15.43 & 18.23 & 71.32 & 15.62 & 519.25 \\
Maximum & 39.93 & 142.93 & 62.38 & 69.34 & 143.64 & 36.39 & 1212.79 \\
Average & 29.16 & 109.98 & 41.47 & 52.37 & 103.47 & 24.44 & 888.29 \\
\hline
\end{tabular}

In the case of $\mathrm{Ni}$, the concentration was less than the average value of the shale at all sample locations. The copper concentrations in the D1 sediment was $69.34 \mathrm{mg} / \mathrm{kg}$, probably from the industrial and urban waste [58]. Metals concentrations in the Weihe River were therefore ranked in descending order: $\mathrm{Mn}>\mathrm{Cr}>\mathrm{Zn}>\mathrm{Cu}>\mathrm{Ni}>\mathrm{As}>\mathrm{Pb}$ (Figure $\mathrm{S} 1$ ).

A comparison of heavy metal concentration with the data of other rivers from literature are listed in Table 4. The Chenab River, Pakistan [59], had low heavy metal concentration, and Axios River, Greece [60], River Po, Italy [61], and Tees River, UK [62], had high concentration as compared with the Weihe River. Moreover, the concentration of metals in the Weihe River sediments was almost at the center of the surveyed rivers in China [63-66]. The results showed that the concentrations of $\mathrm{Cu}, \mathrm{As}$, $\mathrm{Cr}$, and $\mathrm{Ni}$ in the sediments were approximately equal to Zijiang River, Hunan and Yellow River, China. In Jialu River, China, except for As, metal concentrations were almost the same. $\mathrm{Cu}, \mathrm{Cr}, \mathrm{Zn}$, and $\mathrm{Pb}$ are rather low when compared with the Yangtze River, China. In the Weihe River, the concentrations of As, $\mathrm{Cr}$, and Ni were more significant than those in Luanhe River, China. 
Table 4. The concentration of metals in the Weihe River compared with different rivers of the world from literature $(\mathrm{mg} / \mathrm{kg})$.

\begin{tabular}{|c|c|c|c|c|c|c|c|c|}
\hline River & $\mathrm{Cu}$ & As & $\mathrm{Cr}$ & $\mathrm{Ni}$ & Zn & Mn & $\mathbf{P b}$ & Reference \\
\hline Weihe River, Xian, China & $18.23-69.34$ & $18.43-39.93$ & $60.54-142.93$ & $15.43-62.38$ & $71.32-143.64$ & $519.25-1212.79$ & $15.62-36.39$ & This Study \\
\hline Zijiang River, Hunan, China & $18.37-59.01$ & $6.90-74.34$ & 48.47-95.32 & $21.50-52.29$ & $42.41-251.61$ & 570.75-2106.73 & $12.70-104.32$ & [65] \\
\hline Yangtze River, China & 129 & 29.90 & 205 & NA & 1142 & NA & 98 & [66] \\
\hline Jialu River, China & $8.82-107.61$ & $2.39-14.57$ & $40.04-96.39$ & $19.75-80.26$ & $42.39-210.00$ & NA & $14.79-51.17$ & [64] \\
\hline Luanhe River, China & NA & $3.4-13.5$ & $9.6-35.6$ & $3.5-35.8$ & NA & NA & $22.6-43.7$ & [63] \\
\hline Yellow River, China & $30-102$ & $14-48$ & $41-128$ & NA & NA & NA & $26-78$ & [67] \\
\hline Korotoa River, Bangladesh & 76 & 25 & 109 & 95 & NA & NA & 58 & [68] \\
\hline Axios River, Greece & 93 & 40 & 180 & 188 & 271 & NA & 140 & [60] \\
\hline River Po, Italy & 90.1 & NA & NA & 16198.5 & 645 & NA & 98.5 & {$[61]$} \\
\hline Gomti River, India & 245.33 & NA & 88.7 & 76.08 & 343.47 & 834.7 & 156.2 & [69] \\
\hline Chenab River, Pakistan & $5.80-9.40$ & NA & NA & NA & $11.7-50.5$ & $245-851$ & $2.4-32.4$ & [59] \\
\hline Almendares River, Cuba & 420.8 & NA & 23.4 & NA & 708.8 & NA & 189 & [70] \\
\hline Nile River Egypt & 81 & NA & 274 & 112 & 221 & 2810 & 23.2 & [71] \\
\hline South Platte River, USA & 480 & 31 & 71 & NA & 3700 & 6700 & 270 & {$[72]$} \\
\hline Tees River, UK & 76.9 & NA & NA & NA & 1920 & 5240 & 6880 & [62] \\
\hline
\end{tabular}

NA represents "Not Available" 


\subsection{Contamination Level}

\subsubsection{Geo-Accumulation Index (Igeo)}

The Igeo was used to explain the quality of sediment [73]. The values of Igeo from all sampling sites are presented in Figure 2. Igeo values indicated that the Weihe River was not contaminated by $\mathrm{Mn}$ and $\mathrm{Ni}(\mathrm{Igeo}<0)$, "unpolluted to moderately polluted" by $\mathrm{Cr}, \mathrm{Cu}, \mathrm{Zn}$, and $\mathrm{Pb}(\mathrm{Igeo}<1)$, and moderately contaminated by As (Igeo $<2)$. The average Igeo values were ranked as: $\mathrm{As}>\mathrm{Cr}>\mathrm{Pb}>$ $\mathrm{Cu}>\mathrm{Zn}>\mathrm{Mn}>\mathrm{Ni}$ (Figure 2).
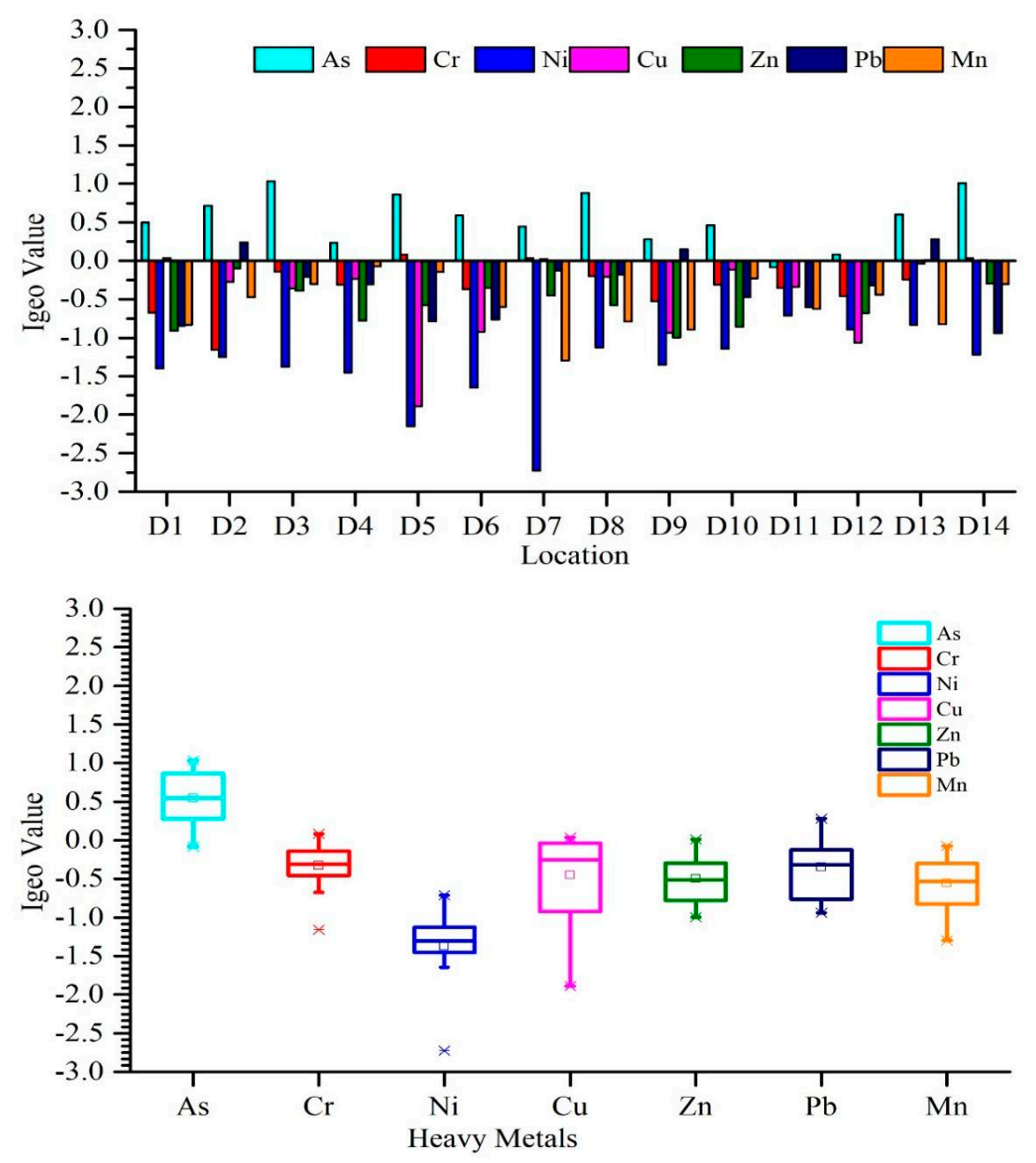

Figure 2. Variation in the (Igeo) values at different study sites in the Weihe River.

\subsubsection{Enrichment Factor (EF)}

EF is a common normalization procedure for classifying metal particles related to sediments. Generally, the average EF value of all the metals studied showed their enrichment in the Weihe River sediments (Figure 3). The highest EF value was found at site D7 (3.35) for As, which indicated deficiency to moderate enrichment. The lowest EF value was found at site D5 (0.25) for Ni, with no enrichment. EF values for As at all sites, except D4, D10, D11, and D12, Cr, and Cu at site D7, and Pb at D7 and D13 are greater than 2 in sediments, which shows deficiency to moderate enrichment. The highest EF value was identified in As, while the minimum in $\mathrm{Ni}$. Pb has the second-highest EF value. 

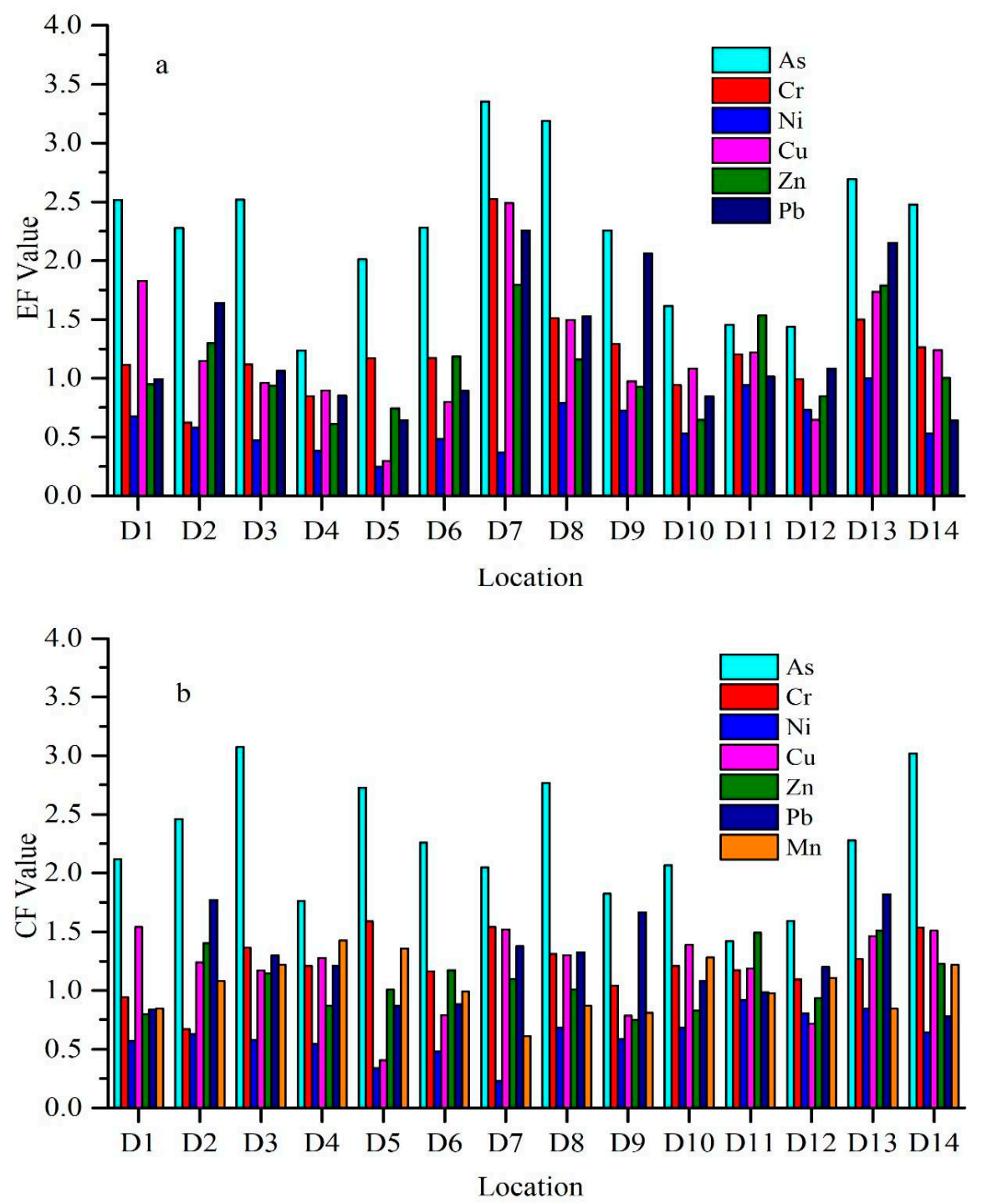

Figure 3. Variation in (a) enrichment factor $(\mathrm{EF})$, (b) contamination factor (CF) from all study stations in the Weihe River.

\subsubsection{Contamination Factor (CF)}

Average $\mathrm{CF}$ concentrations of $\mathrm{As}, \mathrm{Cr}, \mathrm{Ni}, \mathrm{Cu}, \mathrm{Zn}, \mathrm{P}$, and $\mathrm{Mn}$ were 2.24, 1.22, 0.61, 1.16, 1.09, 1.22, and 1.05, respectively. $\mathrm{CF}$ value ranges for $\mathrm{Cr}, \mathrm{Ni}, \mathrm{Cu}, \mathrm{Zn}, \mathrm{Pb}$, and $\mathrm{Mn}$ were 0.67 to $1.59,0.23$ to 0.92 , 0.41 to $1.54,0.75$ to $1.51,0.78$ to 1.82 , and 0.61 to 1.41 , respectively. Among all heavy metals, $\mathrm{Ni}$ had the lowest value at site D7 (0.227), and As the highest value at site D3 (3.07). Average CF values for all metals were ordered as follows: $\mathrm{As}>\mathrm{Pb}>\mathrm{Cr}>\mathrm{Cu}>\mathrm{Zn}>\mathrm{Mn}>\mathrm{Ni}$ (Table S2).

\subsection{Potential Ecological Risk and Risk Index}

Potential ecological risk of single metal, as well as the risk index (RI) of combined metals were measured; findings are shown in Figure 4. The Håkanson Index furnished quantitative techniques for isolating the potential hazard directly. However, its drawbacks are high stage subjectivity and ignorance of combined antagonism, or the weighting role of many heavy metals. In general, a single metal pollution index and risk index produce different results [74]. 


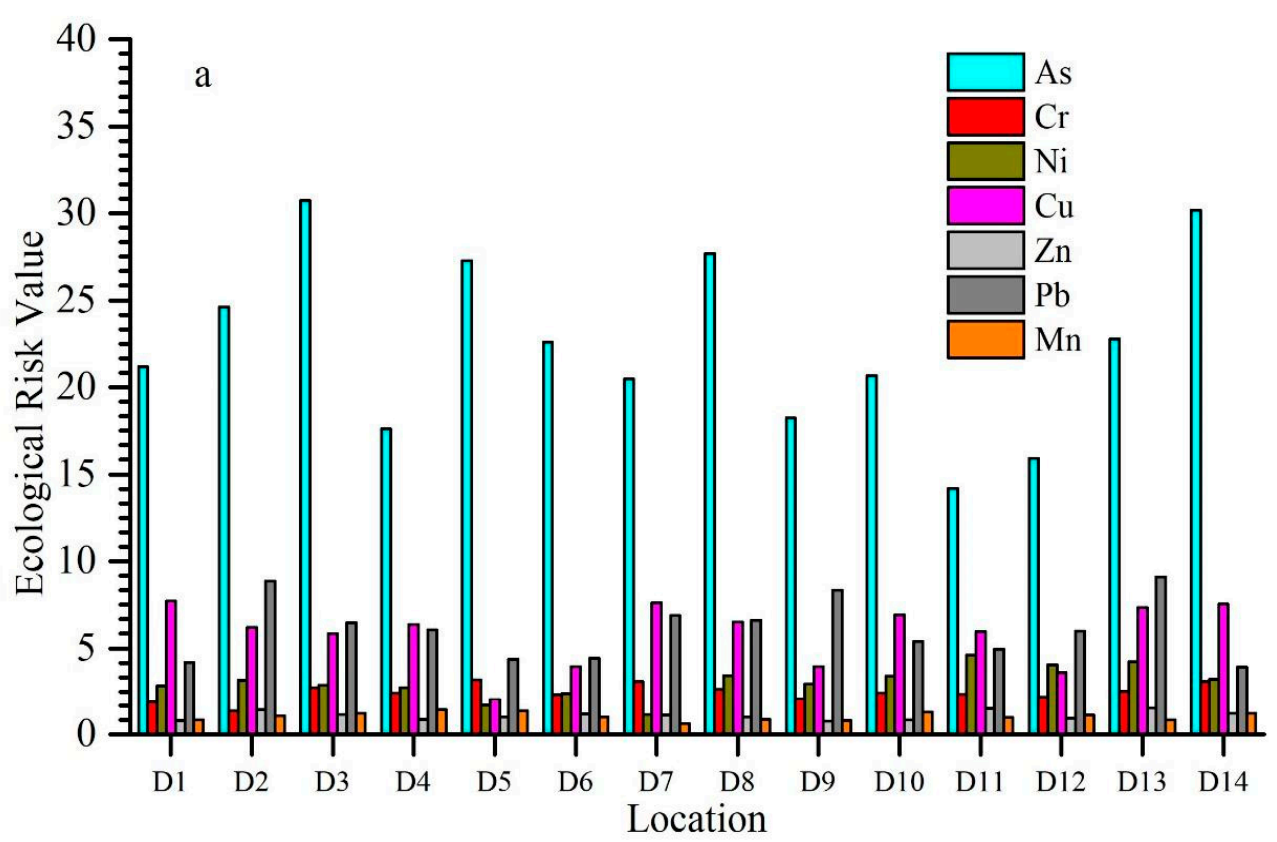

$\mathrm{b}$

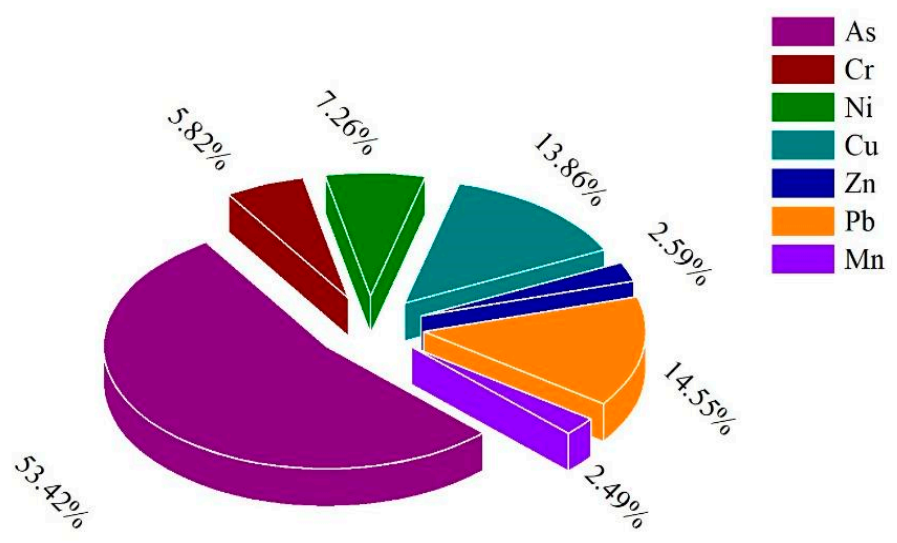

Figure 4. (a) Variation in the ecological risk of metals, (b) average percentage of individual metal in risk index.

Based on the individual ecological risk, the highest ecological risk for arsenic was observed at D3 (30.71), and lowest at D11 (14.18) for chromium, the highest ecological risk at D5 (3.18), for Ni at D11 (4.59), for copper at D1 (7.71), for zinc at D13 (1.51), for lead at D13 (9.10), and Mn at D4 (1.43). The potential ecological risk (PER) for individual metal shows that the degree of metal contamination is in the following sequence: $\mathrm{As}>\mathrm{Pb}>\mathrm{Cu}>\mathrm{Ni}>\mathrm{Cr}>\mathrm{Zn}>\mathrm{Mn}$ (Figure 4).

The maximum risk index found at D3 (51.02), and the minimum risk index was at D12 (33.76). For the contribution of metals in potential risk index (RI), As was regarded as the key potential ecological risk factor, with contributions of $53.43 \%$, and other metals $\mathrm{Cr}, \mathrm{Ni}, \mathrm{Cu}, \mathrm{Zn}, \mathrm{Pb}$, and $\mathrm{Mn}$ contributed $5.82 \%, 7.26 \%, 13.86 \%, 2.59 \%, 14.55 \%$, and $2.49 \%$, respectively. The risk index followed the order of D3 $>$ D14 $>$ D8 $>$ D13 $>$ D2 $>$ D10 $>$ D7 $>$ D5 $>$ D1 $>$ D6 $>$ D4 > D9 > D11 > D12 (Table S2).

\subsection{Correlation among Heavy Metals}

The correlation can identify the source and movement of metals among heavy metals $[55,75]$. Many metal pairs had positive correlations ( $\mathrm{P}<0.01)$ : As- $\mathrm{Cu}(0.092)$, As-Mn (0.214), Ni-Zn (0.361), $\mathrm{Cu}-\mathrm{Zn}(0.203)$, and $\mathrm{Zn}-\mathrm{Pb}(0.242)$. While As-Cr (0.389) displayed a significant positive correlation at $\mathrm{P}<0.05$. In addition, $\mathrm{Cr}-\mathrm{Zn}(0.008)$ and $\mathrm{Ni}-\mathrm{Pb}(0.170)$ showed a relatively weak correlation (Table 5). 
Heavy metals having significant correlations did not mean they originated from the same source, which would depend upon the source and pathway between inter-elements correlation [57,76].

Table 5. Pearson correlation analysis results of metals in sediments.

\begin{tabular}{cccccccc}
\hline & As & $\mathbf{C r}$ & $\mathbf{N i}$ & $\mathbf{C u}$ & $\mathbf{Z n}$ & $\mathbf{P b}$ & $\mathbf{M n}$ \\
\hline $\mathrm{As}$ & 1 & & & & & & \\
$\mathrm{Cr}$ & $0.389^{*}$ & 1 & & & & & \\
$\mathrm{Ni}$ & -0.289 & $-0.380^{* *}$ & 1 & & & & \\
$\mathrm{Cu}$ & $0.092^{* *}$ & -0.032 & 0.157 & 1 & & & \\
$\mathrm{Zn}$ & 0.146 & $0.008^{*}$ & $0.361^{* *}$ & $0.203^{* *}$ & 1 & & \\
$\mathrm{~Pb}$ & -0.083 & -0.367 & $0.170^{*}$ & 0.120 & $0.242^{* *}$ & 1 & \\
$\mathrm{Mn}$ & $0.214^{* *}$ & 0.132 & 0.046 & $-0.286^{*}$ & -0.132 & $-0.365^{* *}$ & 1 \\
\hline
\end{tabular}

* Significant correlation at $p<0.05 .{ }^{* *}$ Significant correlation at $p<0.01$.

PCA was applied to obtain the validity of the source identification of metals through Kaiser-Meyer-Olkin, and is significant, according to the Bartlett's test. The finding of the PCA variation diagram in rotated space, the total variance of "three rotated principal components" (PC) is $66.92 \%$ with eigenvalues $>1$. As and Cr were a heavy fall in PC1 with a total variance of $29.898 \%$, having an eigenvalue of 2.093 . Pb was identified as high loading with $20.203 \%$ of total variance as PC2 (Figure S2). Ni (0.741) and Zn (0.810) were strongly correlated with a total variance of $16.725 \%$ as PC3 (Table 6).

Table 6. Values of rotated component analysis of metals in the Weihe River sediment.

\begin{tabular}{cccc}
\hline \multirow{2}{*}{ Metals } & \multicolumn{3}{c}{ Components } \\
\cline { 2 - 4 } & $\mathbf{1}$ & $\mathbf{2}$ & $\mathbf{3}$ \\
\hline $\mathrm{As}$ & $\mathbf{0 . 8 0 5}$ & -0.049 & 0.164 \\
$\mathrm{Cr}$ & $\mathbf{0 . 7 8 8}$ & -0.157 & -0.153 \\
$\mathrm{Ni}$ & -0.510 & -0.112 & $\mathbf{0 . 7 4 1}$ \\
$\mathrm{Cu}$ & 0.205 & 0.551 & 0.352 \\
$\mathrm{Zn}$ & 0.164 & 0.218 & $\mathbf{0 . 8 1 0}$ \\
$\mathrm{Pb}$ & -0.308 & $\mathbf{0 . 6 2 3}$ & 0.213 \\
$\mathrm{Mn}$ & 0.126 & -0.868 & 0.140 \\
Eigenvalue & 2.093 & 1.421 & 1.171 \\
\% Total variance & 29.898 & 20.203 & 16.725 \\
Cumulative \% variance & 29.898 & 50.201 & 66.926 \\
\hline
\end{tabular}

PCA values $>0.6$ are presented in bold.

\section{Discussion}

The average concentration of $\mathrm{Cr}, \mathrm{Ni}, \mathrm{Cu}, \mathrm{Zn}$, and $\mathrm{Pb}$ is higher than the value in the "Weihe River basin" [77]. Cr concentration is a consequence of straight discharging and unprocessed waste from different textile industries and tanneries [78]. Cr exists in several valence states from -2 to +6 , among which "0 (elemental metal), +3 (trivalent), and +6 (hexavalent)" are the most stable states. The health effect of $\mathrm{Cr}$ is related to the valence state of metal at the time of exposure. Biologically trivalent and hexavalent are considered to be the most important, where trivalent is an essential nutritional mineral [79]. Arsenic is regarded as toxic to humans as well as to aquatic organisms [10].

Excessive concentration of As can be connected to anthropogenic activities, for example, fertilizer used for agriculture, arsenical pesticides, copper arsenate treatment of wood, as well as tanning with certain chemicals, more likely arsenic sulfide [8,80]. $\mathrm{Cu}$ and $\mathrm{Zn}$ are important micronutrients for aquatic organisms, but toxic at high levels [10]. In sediments, metals were linked to their nearby traffic activities, i.e., copper used in car lubricant, chromium in alloy steel for auto parts, and stainless steel [8].

Overall, the concentration of metals in the studied area was relatively in between as compared with other rivers in China and the world. The concentration of $\mathrm{As}, \mathrm{Cr}$, and $\mathrm{Ni}$ in the Weihe River is 
greater than in the Luanhe River, China; and $\mathrm{Cu}, \mathrm{Cr}$, and $\mathrm{Zn}$ are less when compared to the Yangtze River, China. The Yellow River, Zijiang River, Hunan, and the Weihe River have nearly the same concentration of these metals (Table 4). Earlier studies in the Shaanxi basin clarified that sediments were mainly polluted by $\mathrm{Cd}$ in the Weihe River $[1,77]$. Major contents of metals were generated by an anthropogenic effect [81].

The Igeo was used to measure the different pollution levels in sediments. According to our results, most of the sites in the Weihe River were uncontaminated (class 0 ) because Igeo values were less than zero. Through all heavy metals, As has maximum accumulation at D3 and D14, which indicates that the sediments at these locations are moderately polluted by As and belong to class 2 . Additionally, at few stations, the Igeo concentrations for the $\mathrm{Cr}, \mathrm{Cu}, \mathrm{Zn}$, and $\mathrm{Pb}$ are greater than zero, which shows the minimal presence of $\mathrm{Cr}, \mathrm{Cu}, \mathrm{Zn}$, and $\mathrm{Pb}$, and places in class 1 "Uncontaminated to moderately contaminate". However, the average values of Igeo for $\mathrm{Cr}, \mathrm{Cu}$, and $\mathrm{Zn}$ are less than zero. Moreover, arsenic had several positive values (greater than 0 ), which specify that the sediments are moderately contaminated by arsenic.

EF can be used to distinguish between sources of the element, which may be anthropogenic or natural. The sediments that have EF value between 0 and 1.5 suggest that their origin is natural or derived from crustal material. On the other hand, $E F>1.5$ indicates that these originated through anthropogenic activities. If the $\mathrm{EF}$ value is higher than 10 , then these metals were considered non-crusted sources [82]. The average EF value for As was higher than 1.5, which suggests an anthropogenic effect on metals. The average $\mathrm{EF}$ values for $\mathrm{Cr}, \mathrm{Ni}, \mathrm{Cu}, \mathrm{Zn}$, and $\mathrm{Pb}$ were less than 1.5 , which indicates the crustal or natural origin. $\mathrm{Cr}$ at site D7 and D8, Cu at D1, D7, and D13, Zn D11 and D13 and Pb at sites D2, D7, D8, D9, and D13, have EF values more than 1.5, which shows that the origin of these metals at these sites are most probably anthropogenic [82]. EF values below 5.0 will not be regarded significant, for the reason that such minor enrichments may result from differences within the composition of neighborhood soil materials along with reference sediment utilized in EF calculations [83].

Contamination factor results show that the Weihe River is moderately contaminated by $\mathrm{As}, \mathrm{Cr}, \mathrm{Cu}$, $\mathrm{Zn}, \mathrm{Mn}$, and $\mathrm{Pb}$, with a low contamination by $\mathrm{Ni}$. As has a maximum value of $\mathrm{CF}$ at sites D3 and D14, indicating these sites being considerably contaminated, whereas D11 showed moderate contamination.

Potential ecological risk results elucidated that the highest ecological risk (ER) is for arsenic, and the lowest risk is for manganese. The ecological risk values of all metals were below 30, suggesting a slight pollution level. Only As at D3 had an ER value of more than 30, which is not a severe threat for ecology. In general, all measured metals had low ecological risk across all stations. Regarding risk index, As is the major contributor, and the other metals, $\mathrm{Ni}, \mathrm{Cr}, \mathrm{Cu}, \mathrm{Zn}, \mathrm{Pb}$, and $\mathrm{Mn}$ exhibited low potential ecological risk indices. According to the risk index, sampling site D3 has a maximum risk index, and site D12 shows a minimum risk index. Our study showed the PER $<40$ and RI $<110$ for the Weihe River, which is solid evidence of low risk of these metals in the subjective area.

The principal component analysis was performed to compare the pattern between the heavy metals. PCA of the whole data set showed three PCs with eigenvalues $>0.6$ that illuminated about $66.92 \%$. The first component accumulated for $29.89 \%$, correlated (loading $>0.6$ ) with As and $\mathrm{Cr}$, indicating the similar distribution patterns. While, the second component accumulated for $20.20 \%$, correlated with $\mathrm{Pb}$. However, $\mathrm{Pb}$ is the only element in the second component, which had a large load and measurement among all the other elements, and the concentration of this element is higher than background values. The third component of $16.72 \%$, and correlated (loading $>0.6$ ) with $\mathrm{Ni}$ and $\mathrm{Zn}$ by showing high concentrations and primarily distributed in the sediments. Pearson correlation analysis indicates that As had a strongly positive significant correlation with $\mathrm{Cr}$, $\mathrm{Cu}$, and $\mathrm{Mn}$, which revealed they were of the same source. However, $\mathrm{Cr}$ was negatively correlated with $\mathrm{Ni}$, and $\mathrm{Zn}$, which demonstrated that these metals could be from different sources. Similarly, $\mathrm{Cu}$ and $\mathrm{Pb}$ had a significant negative relationship with $\mathrm{Mn}$, indicating the pair to have originated from different sources. Although these heavy metals have no severe risk, measures should be taken to stop heavy metals pollution in the studied area. 


\section{Conclusions}

Sediment samples from fourteen sites have been taken, and heavy metals in the samples were ranked as follows: "Manganese $(\mathrm{Mn})>\operatorname{chromium}(\mathrm{Cr})>\operatorname{zinc}(\mathrm{Zn})>\operatorname{copper}(\mathrm{Cu})>\operatorname{nickel}(\mathrm{Ni})>$ arsenic $(\mathrm{As})>$ lead $(\mathrm{Pb})$ ". To measure the contamination levels in the Weihe River, "geo accumulation index, enrichment factor and contamination factor" have been utilized. Further, the potential ecological risk and risk index have been calculated to evaluate the ecological risk of heavy metals. According to the geo-accumulation index, As belonged to class 1 (uncontaminated to moderate contamination), while $\mathrm{Cr}, \mathrm{Ni}, \mathrm{Cu}, \mathrm{Zn}, \mathrm{Pb}$, and $\mathrm{Mn}$ belonged to class 0 (uncontaminated). According to the enrichment factor, As was originated through anthropogenic activities, and the $\mathrm{Cr}, \mathrm{Ni}, \mathrm{Cu}, \mathrm{Zn}$, and $\mathrm{Pb}$ were from a natural source. The potential ecological risk and total risk index were less than 40 and 110, respectively, which indicates that these heavy metals have low ecological risk. In the risk index, As showed the highest contribution at $53.43 \%$, and $\mathrm{Cr}, \mathrm{Ni}, \mathrm{Cu}, \mathrm{Zn}, \mathrm{Pb}$, and $\mathrm{Mn}$ were $5.82 \%, 7.26 \%, 13.86 \%, 2.59 \%, 14.55 \%$, and $2.49 \%$, respectively. According to the correlation matrix, a significant positive correlation existed among the following pairs: (As, $\mathrm{Cr}),(\mathrm{As}, \mathrm{Mn})$, and $(\mathrm{Ni}, \mathrm{Zn})$, while relatively weak positive correlation has been found within pairs $(\mathrm{Cr}, \mathrm{Zn})$ and $(\mathrm{Ni}, \mathrm{Pb})$. Lastly, a negative correlation existed among $(\mathrm{Cr}, \mathrm{Ni})$, $(\mathrm{Cu}, \mathrm{Mn})$, and $(\mathrm{Pb}, \mathrm{Mn})$.

Supplementary Materials: The following are available online at http://www.mdpi.com/1660-4601/17/3/1070/s1, Figure S1: variation in concentrations of heavy metal in the sediment collected from different stations of the Weihe River. Figure S2: three principal components plot in the principal component analysis (PCA). Table S1: background concentration of heavy metals used in this study. Table S2: variation in contamination levels "geo accumulation index (Igeo), enrichment factor (EF), contamination factor (CF), ecological risk (ER), and risk index (RI)" in the Weihe River.

Author Contributions: M.I.A. and J.S. designed the study. M.I.A., X.W., and H.S. executed the work and analyzed the data. M.I.A., M.S.M., M.S. and P.S. wrote the manuscript. M.S.M. and P.S. worked on software to draw the map, graph, and diagram. M.I.A., M.S., A.J.K. and J.S. contributed to the manuscript preparation and proofreading. J.S. supervised the execution of the work. All authors have read and approved the final version of the manuscript.

Funding: This study was jointly supported by the National Natural Science Foundation of China (Grant Nos. 51679200 and 51379175), The Key Research and Development Program of Shaanxi (Grant No. 2019ZDLSF05-02), and Science and Technology Project of Shaanxi Provincial Water Resources Department (Grant No. 2018slkj-12).

Acknowledgments: We thank Fazeel Abid, Adnan Altaf Raza, Zeeshan Zafar, Rana Muhammad Zulqarnain, Muhammad Ali Raza and Muhammad Adeel for their valuable suggestions. Primarily, we are grateful to the editor and anonymous reviewers for providing numerous comments and suggestions, which helped to improve this manuscript.

Conflicts of Interest: The authors declare no conflict of interest.

\section{References}

1. Song, J.; Yang, X.; Zhang, J.; Long, Y.; Zhang, Y. Assessing the variability of heavy metal concentrations in liquid-solid two-phase and related environmental risks in the weihe river of Shaanxi province, China. Int. J. Environ. Res. Public Health 2015, 12, 8243-8262. [CrossRef]

2. Butturini, A.; Bernal, S.; Sabater, S.; Sabater, F. The influence of riparian-hyporheic zone on the hydrological responses in an intermittent stream. Hydrol. Earth Syst. Sci. 2010, 6, 515-526. [CrossRef]

3. Ocampo-Duque, W.; Osorio, C.; Piamba, C.; Schuhmacher, M.; Domingo, J.L. Water quality analysis in rivers with non-parametric probability distributions and fuzzy inference systems: Application to the Cauca River, Colombia. Environ. Int. 2013, 52, 17-28. [CrossRef] [PubMed]

4. Jacobson, P.J.; Jacobson, K.M. Hydrologic controls of physical and ecological processes in Namib Desert ephemeral rivers: Implications for conservation and management. J. Arid Environ. 2013, 93, 80-93. [CrossRef]

5. Ayllón, D.; Almodóvar, A.; Nicola, G.G.; Parra, I.; Elvira, B. Modelling carrying capacity dynamics for the conservation and management of territorial Salmonids. Fish. Res. 2012, 134-136, 95-103. [CrossRef]

6. Nilin, J.; Moreira, L.B.; Aguiar, J.E.; Marins, R.; Moledo de Souza Abessa, D.; Monteiro da Cruz Lotufo, T.; Costa-Lotufo, L.V. Sediment quality assessment in a tropical estuary: The case of Ceará River, Northeastern Brazil. Mar. Environ. Res. 2013, 91, 89-96. [CrossRef] 
7. Cui, N.; Wu, J.; Xiang, D.; Cheng, S.; Zhou, Q. A field study on seed bank and its potential applications in vegetation restoration of a polluted urban river in China. Ecol. Eng. 2013, 60, 37-44. [CrossRef]

8. Fu, J.; Zhao, C.; Luo, Y.Y.; Liu, C.; Kyzas, G.Z.; Luo, Y.Y.; Zhao, D.; An, S.; Zhu, H. Heavy metals in surface sediments of the Jialu River, China: Their relations to environmental factors. J. Hazard. Mater. 2014, 270, 102-109. [CrossRef]

9. Ji, K.; Kim, J.; Lee, M.; Park, S.; Kwon, H.J.; Cheong, H.K.; Jang, J.Y.; Kim, D.S.; Yu, S.; Kim, Y.W.; et al. Assessment of exposure to heavy metals and health risks among residents near abandoned metal mines in Goseong, Korea. Environ. Pollut. 2013, 178, 322-328. [CrossRef]

10. Bastami, K.D.; Bagheri, H.; Kheirabadi, V.; Zaferani, G.G.; Teymori, M.B.; Hamzehpoor, A.; Soltani, F.; Haghparast, S.; Harami, S.R.M.; Ghorghani, N.F.; et al. Distribution and ecological risk assessment of heavy metals in surface sediments along southeast coast of the Caspian Sea. Mar. Pollut. Bull. 2014, 81, 262-267. [CrossRef]

11. Xiao, R.; Bai, J.; Lu, Q.; Zhao, Q.; Gao, Z.; Wen, X.; Liu, X. Fractionation, transfer, and ecological risks of heavy metals in riparian and ditch wetlands across a 100-year chronosequence of reclamation in an estuary of China. Sci. Total Environ. 2015, 517, 66-75. [CrossRef] [PubMed]

12. Suresh, G.; Ramasamy, V.; Sundarrajan, M.; Paramasivam, K. Spatial and vertical distributions of heavy metals and their potential toxicity levels in various beach sediments from high-background-radiation area, Kerala, India. Mar. Pollut. Bull. 2015, 91, 389-400. [CrossRef] [PubMed]

13. Duman, F.; Aksoy, A.; Demirezen, D. Seasonal variability of heavy metals in surface sediment of Lake Sapanca, Turkey. Environ. Monit. Assess. 2007, 133, 277-283. [CrossRef] [PubMed]

14. Deniseger, J.; Roch, M.; Clark, M.J.R. The effects of decreasing heavy metal concentrations on the biota of Buttle Lake. Water Res. 1990, 24, 403-416. [CrossRef]

15. Singh, M.; Ansari, A.A.; Müller, G.; Singh, I.B. Heavy metals in freshly deposited sediments of the Gomati River (a tributary of the Ganga River) effects of human activities. Environ. Geol. 1997, 29, 246-252. [CrossRef]

16. Calmano, W.; Ahlf, W.; Förstner, U. Exchange of Heavy Metals Between Sediment Components and Water. In Metal Speciation in the Environment; Springer: Berlin/Heidelberg, Germany, 1990; pp. 503-522.

17. Batley, G.E. Trace Element Specification: Analytical Methods and Problems; CRC Press: Boca Raton, FL, USA, 2000; ISBN 9780849347122.

18. Gao, L.; Wang, Z.; Shan, J.; Chen, J.; Tang, C.; Yi, M.; Zhao, X. Distribution characteristics and sources of trace metals in sediment cores from a trans-boundary watercourse: An example from the Shima River, Pearl River Delta. Ecotoxicol. Environ. Saf. 2016, 134, 186-195. [CrossRef]

19. Ali, M.M.; Ali, M.L.; Islam, M.S.; Rahman, M.Z. Preliminary assessment of heavy metals in water and sediment of Karnaphuli River, Bangladesh. Environ. Nanotechnol. Monit. Manag. 2016, 5, 27-35. [CrossRef]

20. Malvandi, H. Preliminary evaluation of heavy metal contamination in the Zarrin-Gol River sediments, Iran. Mar. Pollut. Bull. 2017, 117, 547-553. [CrossRef]

21. Peng, J.F.; Song, Y.H.; Yuan, P.; Cui, X.Y.; Qiu, G.L. The remediation of heavy metals contaminated sediment. J. Hazard. Mater. 2009, 161, 633-640. [CrossRef]

22. Dong, X.; Wang, C.; Li, H.; Wu, M.; Liao, S.; Zhang, D.; Pan, B. The sorption of heavy metals on thermally treated sediments with high organic matter content. Bioresour. Technol. 2014, 160, 123-128. [CrossRef]

23. Sun, Z.; Mou, X.; Tong, C.; Wang, C.; Xie, Z.; Song, H.; Sun, W.; Lv, Y. Spatial variations and bioaccumulation of heavy metals in intertidal zone of the Yellow River estuary, China. Catena 2015, 126, 43-52. [CrossRef]

24. Muhammad, S.; Shah, M.T.; Khan, S. Heavy metal concentrations in soil and wild plants growing around $\mathrm{Pb}-\mathrm{Zn}$ sulfide terrain in the Kohistan region, northern Pakistan. Microchem. J. 2011, 99, 67-75. [CrossRef]

25. Altın, A.; Filiz, Z.; Iscen, C.F. Assessment of seasonal variations of surface water quality characteristics for Porsuk Stream. Environ. Monit. Assess. 2009, 158, 51-65. [CrossRef] [PubMed]

26. Damian, F.; Damian, G.; Lăcătuşu, R.; Iepure, G. Heavy metals concentration of the soils around Zlatna and Copşa Mică Smelters Romania. Carpathian J. Earth Environ. Sci. 2008, 3, 65-82.

27. Pekey, H.; Karakaş, D.; Bakoğlu, M. Source apportionment of trace metals in surface waters of a polluted stream using multivariate statistical analyses. Mar. Pollut. Bull. 2004, 49, 809-818. [CrossRef]

28. Dong, A.; Zhai, S.; Matthias, Z.; Yu, Z.; Zhang, H.; Liu, F. Heavy metals in Changjiang estuarine and offshore sediments: Responding to human activities. Acta Oceanol. Sin. 2012, 31, 88-101. [CrossRef] 
29. Zhao, S.; Feng, C.; Wang, D.; Liu, Y.; Shen, Z. Salinity increases the mobility of Cd, Cu, Mn, and Pb in the sediments of Yangtze Estuary: Relative role of sediments' properties and metal speciation. Chemosphere 2013, 91, 977-984. [CrossRef]

30. Olawoyin, R.; Oyewole, S.A.; Grayson, R.L. Potential risk effect from elevated levels of soil heavy metals on human health in the Niger delta. Ecotoxicol. Environ. Saf. 2012, 85, 120-130. [CrossRef]

31. Adeel, M.; Lee, J.Y.; Zain, M.; Rizwan, M.; Nawab, A.; Ahmad, M.A.; Shafiq, M.; Yi, H.; Jilani, G.; Javed, R.; et al. Cryptic footprints of rare earth elements on natural resources and living organisms. Environ. Int. 2019, 127, 785-800. [CrossRef]

32. Hejna, M.; Gottardo, D.; Baldi, A.; Dell'Orto, V.; Cheli, F.; Zaninelli, M.; Rossi, L. Review: Nutritional ecology of heavy metals. Animal 2018, 12, 2156-2170. [CrossRef]

33. Chang, J.; Wang, Y.; Istanbulluoglu, E.; Bai, T.; Huang, Q.; Yang, D.; Huang, S. Impact of climate change and human activities on runoff in the Weihe River Basin, China. Quat. Int. 2015, 380-381, 169-179. [CrossRef]

34. Song, J.; Xu, Z.; Hui, Y.; Li, H.; Li, Q. Instream flow requirements for sediment transport in the lower Weihe River. Hydrol. Process. 2010, 24, 3547-3557. [CrossRef]

35. Gao, L.; Gao, B.; Xu, D.; Peng, W.; Lu, J. Multiple assessments of trace metals in sediments and their response to the water level fluctuation in the Three Gorges Reservoir, China. Sci. Total Environ. 2019, 648, 197-205. [CrossRef] [PubMed]

36. Varol, M. Assessment of heavy metal contamination in sediments of the Tigris River (Turkey) using pollution indices and multivariate statistical techniques. J. Hazard. Mater. 2011, 195, 355-364. [CrossRef] [PubMed]

37. Chandrasekaran, A.; Ravisankar, R.; Harikrishnan, N.; Satapathy, K.K.; Prasad, M.V.R.; Kanagasabapathy, K.V. Multivariate statistical analysis of heavy metal concentration in soils of Yelagiri Hills, Tamilnadu, India Spectroscopical approach. Spectrochim. Acta Part A Mol. Biomol. Spectrosc. 2015, 137, 589-600. [CrossRef] [PubMed]

38. Bhuiyan, M.A.H.; Parvez, L.; Islam, M.A.; Dampare, S.B.; Suzuki, S. Heavy metal pollution of coal mine-affected agricultural soils in the northern part of Bangladesh. J. Hazard. Mater. 2010, 173, 384-392. [CrossRef]

39. Mohiuddin, K.M.; Zakir, H.M.; Otomo, K.; Sharmin, S.; Shikazono, N. Geochemical distribution of trace metal pollutants in water and sediments of downstream of an urban river. Int. J. Environ. Sci. Technol. 2010, 7, 17-28. [CrossRef]

40. Santos Bermejo, J.C.; Beltrán, R.; Gömez Ariza, J.L. Spatial variations of heavy metals contamination in sediments from Odiel river (Southwest Spain). Environ. Int. 2003, 29, 69-77. [CrossRef]

41. Turekian, K.K.; Wedepohl, K.H. Distribution of some major elements of the Earth's crust. Geol. Soc. Am. Bull. 1961, 72, 175-192. [CrossRef]

42. Franco-Uría, A.; López-Mateo, C.; Roca, E.; Fernández-Marcos, M.L. Source identification of heavy metals in pastureland by multivariate analysis in NW Spain. J. Hazard. Mater. 2009, 165, 1008-1015. [CrossRef]

43. Sinex, S.A.; Helz, G.R. Regional geochemistry of trace elements in Chesapeake Bay sediments. Environ. Geol. 1981, 3, 315-323. [CrossRef]

44. Selvaraj, K.; Ram Mohan, V.; Szefer, P. Evaluation of metal contamination in coastal sediments of the Bay of Bengal, India: Geochemical and statistical approaches. Mar. Pollut. Bull. 2004, 49, 174-185. [CrossRef] [PubMed]

45. Sayadi, M.H.; Sayyed, M.R.G.; Kumar, S. Short-term accumulative signatures of heavy metals in river bed sediments in the industrial area, Tehran, Iran. Environ. Monit. Assess. 2010, 162, 465-473. [CrossRef]

46. Salati, S.; Moore, F. Assessment of heavy metal concentration in the Khoshk River water and sediment, Shiraz, Southwest Iran. Environ. Monit. Assess. 2010, 164, 677-689. [CrossRef]

47. Amin, B.; Ismail, A.; Arshad, A.; Yap, C.K.; Kamarudin, M.S. Anthropogenic impacts on heavy metal concentrations in the coastal sediments of Dumai, Indonesia. Environ. Monit. Assess. 2009, 148, 291-305. [CrossRef]

48. Loska, K.; Wiechula, D.; Barska, B.; Cebula, E.; Chojnecka, A. Assessment of arsenic enrichment of cultivated soils in Southern Poland. Polish J. Environ. Stud. 2003, 12, 187-192.

49. Birch, G.F.; Olmos, M.A. Sediment-bound heavy metals as indicators of human influence and biological risk in coastal water bodies. ICES J. Mar. Sci. 2008, 65, 1407-1413. [CrossRef]

50. Sakan, S.M.; Dordević, D.S.; Manojlović, D.D.; Predrag, P.S. Assessment of heavy metal pollutants accumulation in the Tisza river sediments. J. Environ. Manag. 2009, 90, 3382-3390. [CrossRef] 
51. Hakanson, L. Stress testing and the new technetium-99m cardiac imaging agents. Am. J. Card. Imaging 1979, 5, 32-36.

52. Pejman, A.; Nabi Bidhendi, G.; Ardestani, M.; Saeedi, M.; Baghvand, A. A new index for assessing heavy metals contamination in sediments: A case study. Ecol. Indic. 2015, 58, 365-373. [CrossRef]

53. Chai, L.; Li, H.; Yang, Z.; Min, X.; Liao, Q.; Liu, Y.; Men, S.; Yan, Y.; Xu, J. Heavy metals and metalloids in the surface sediments of the Xiangjiang River, Hunan, China: Distribution, contamination, and ecological risk assessment. Environ. Sci. Pollut. Res. 2017, 24, 874-885. [CrossRef]

54. Ke, X.; Gui, S.; Huang, H.; Zhang, H.; Wang, C.; Guo, W. Ecological risk assessment and source identification for heavy metals in surface sediment from the Liaohe River protected area, China. Chemosphere 2017, 175, 473-481. [CrossRef] [PubMed]

55. Wang, Y.; Hu, J.; Xiong, K.; Huang, X.; Duan, S. Distribution of Heavy Metals in Core Sediments from Baihua Lake. Procedia Environ. Sci. 2012, 16, 51-58. [CrossRef]

56. Alyazichi, Y.M.; Jones, B.G.; McLean, E.; Pease, J.; Brown, H. Geochemical Assessment of Trace Element Pollution in Surface Sediments from the Georges River, Southern Sydney, Australia. Arch. Environ. Contam. Toxicol. 2017, 72, 247-259. [CrossRef] [PubMed]

57. Ma, L.; Yang, Z.; Li, L.; Wang, L. Source identification and risk assessment of heavy metal contaminations in urban soils of Changsha, a mine-impacted city in Southern China. Environ. Sci. Pollut. Res. 2016, 23, 17058-17066. [CrossRef] [PubMed]

58. Mohiuddin, K.M.; Otomo, K.; Ogawa, Y.; Shikazono, N. Seasonal and spatial distribution of trace elements in the water and sediments of the Tsurumi River in Japan. Environ. Monit. Assess. 2012, 184, 265-279. [CrossRef]

59. Hanif, N.; Eqani, S.A.M.A.S.; Ali, S.M.; Cincinelli, A.; Ali, N.; Katsoyiannis, I.A.; Tanveer, Z.I.; Bokhari, H. Geo-accumulation and enrichment of trace metals in sediments and their associated risks in the Chenab River, Pakistan. J. Geochem. Explor. 2016, 165, 62-70. [CrossRef]

60. Karageorgis, A.; Nikolaidis, N.; Karamanos, H.; Skoulikidis, N. Water and sediment quality assessment of the Axios River and its coastal environment. Cont. Shelf Res. 2003, 23, 1929-1944. [CrossRef]

61. Farkas, A.; Erratico, C.; Viganò, L. Assessment of the environmental significance of heavy metal pollution in surficial sediments of the River Po. Chemosphere 2007, 68, 761-768. [CrossRef]

62. Hudson-Edwards, K.A.; Macklin, M.G.; Taylor, M.P. 2000 years of sediment-borne heavy metal storage in the Yorkshire Ouse basin, NE England, UK. Hydrol. Process. 1999, 13, 1087-1102. [CrossRef]

63. Liu, J.; Yin, P.; Chen, B.; Gao, F.; Song, H.; Li, M. Distribution and contamination assessment of heavy metals in surface sediments of the Luanhe River Estuary, northwest of the Bohai Sea. Mar. Pollut. Bull. 2016, 109, 633-639. [CrossRef] [PubMed]

64. Fu, Z.; Wu, F.; Mo, C.; Liu, B.; Zhu, J.; Deng, Q.; Liao, H.; Zhang, Y. Bioaccumulation of antimony, arsenic, and mercury in the vicinities of a large antimony mine, China. Microchem. J. 2011, 97, 12-19. [CrossRef]

65. Zhang, Z.; Lu, Y.; Li, H.; Tu, Y.; Liu, B.; Yang, Z. Assessment of heavy metal contamination, distribution and source identification in the sediments from the Zijiang River, China. Sci. Total Environ. 2018, 645, 235-243. [CrossRef] [PubMed]

66. Yang, Z.; Wang, Y.; Shen, Z.; Niu, J.; Tang, Z. Distribution and speciation of heavy metals in sediments from the mainstream, tributaries, and lakes of the Yangtze River catchment of Wuhan, China. J. Hazard. Mater. 2009, 166, 1186-1194. [CrossRef]

67. Liu, C.C.; Xu, J.; Liu, C.C.; Zhang, P.; Dai, M. Heavy metals in the surface sediments in Lanzhou Reach of Yellow River, China. Bull. Environ. Contam. Toxicol. 2009, 82, 26-30. [CrossRef]

68. Islam, M.S.; Ahmed, M.K.; Raknuzzaman, M.; Habibullah -Al- Mamun, M.; Islam, M.K. Heavy metal pollution in surface water and sediment: A preliminary assessment of an urban river in a developing country. Ecol. Indic. 2015, 48, 282-291. [CrossRef]

69. Singh, K.P.; Malik, A.; Sinha, S.; Singh, V.K.; Murthy, R.C. Estimation of Source of Heavy Metal Contamination in Sediments of Gomti River (India) using Principal Component Analysis. Water Air Soil Pollut. 2005, 166, 321-341. [CrossRef]

70. Olivares-Rieumont, S.; de la Rosa, D.; Lima, L.; Graham, D.W.; D’Alessandro, K.; Borroto, J.; Martínez, F.; Sánchez, J. Assessment of heavy metal levels in Almendares River sediments-Havana City, Cuba. Water Res. 2005, 39, 3945-3953. [CrossRef]

71. Rifaat, A.E. Major controls of metals distribution in sediments of the Nile Delta, Egypt. Egypt. J. Aquat. Res. $2005,31,16-28$. 
72. Heiny, J.S.; Tate, C.M. Concentration, Distribution, and Comparison of Selected Trace Elements in Bed Sediment and Fish Tissue in the South Platte River Basin, USA, 1992-1993. Arch. Environ. Contam. Toxicol. 1997, 32, 246-259. [CrossRef]

73. Karbassi, A.R.; Monavari, S.M.; Nabi Bidhendi, G.R.; Nouri, J.; Nematpour, K. Metal pollution assessment of sediment and water in the Shur River. Environ. Monit. Assess. 2008, 147, 107-116. [CrossRef]

74. Maanan, M.M.; Saddik, M.; Maanan, M.M.; Chaibi, M.; Assobhei, O.; Zourarah, B. Environmental and ecological risk assessment of heavy metals in sediments of Nador lagoon, Morocco. Ecol. Indic. 2015, 48, 616-626. [CrossRef]

75. Suresh, G.; Ramasamy, V.; Meenakshisundaram, V.; Venkatachalapathy, R.; Ponnusamy, V. Influence of mineralogical and heavy metal composition on natural radionuclide concentrations in the river sediments. Appl. Radiat. Isot. 2011, 69, 1466-1474. [CrossRef]

76. Jørgensen, N.; Laursen, J.; Viksna, A.; Pind, N.; Holm, P.E. Multi-elemental EDXRF mapping of polluted soil from former horticultural land. Environ. Int. 2005, 31, 43-52. [CrossRef]

77. Wang, X.; Su, P.; Lin, Q.; Song, J.; Sun, H.; Cheng, D.; Wang, S.; Peng, J.; Fu, J. Distribution, assessment and coupling relationship of heavy metals and macroinvertebrates in sediments of the Weihe River Basin. Sustain. Cities Soc. 2019, 50, 101665. [CrossRef]

78. Facetti, J.; Dekov, V.M.; Van Grieken, R. Heavy metals in sediments from the Paraguay river: A preliminary study. Sci. Total Environ. 1998, 209, 79-86. [CrossRef]

79. Paine, A.J. Mechanisms of chromium toxicity, carcinogenicity and allergenicity: Review of the literature from 1985 to 2000. Hum. Exp. Toxicol. 2001, 20, 439-451.

80. Bhuiyan, M.A.H.; Suruvi, N.I.; Dampare, S.B.; Islam, M.A.; Quraishi, S.B.; Ganyaglo, S.; Suzuki, S. Investigation of the possible sources of heavy metal contamination in lagoon and canal water in the tannery industrial area in Dhaka, Bangladesh. Environ. Monit. Assess. 2011, 175, 633-649. [CrossRef]

81. Hazarika, N.; Srivastava, A.; Das, A. Quantification of particle bound metallic load and PAHs in urban environment of Delhi, India: Source and toxicity assessment. Sustain. Cities Soc. 2017, 29, 58-67. [CrossRef]

82. Zhang, J.; Liu, C.L. Riverine composition and estuarine geochemistry of particulate metals in China-Weathering features, anthropogenic impact and chemical fluxes. Estuar. Coast. Shelf Sci. 2002, 54, 1051-1070. [CrossRef]

83. Sezgin, N.; Ozcan, H.K.; Demir, G.; Nemlioglu, S.; Bayat, C. Determination of heavy metal concentrations in street dusts in Istanbul E-5 highway. Environ. Int. 2004, 29, 979-985. [CrossRef] 